\title{
Angiotensin-Converting Enzyme 2 (ACE2) Is a Key Modulator of the Renin Angiotensin System in Health and Disease
}

\author{
Chris Tikellis and M. C. Thomas \\ Division of Diabetic Complications, Baker IDI Heart and Diabetes Institute, P.O. Box 6492 Melbourne, VIC 8008, Australia \\ Correspondence should be addressed to Chris Tikellis, chris.tikellis@bakeridi.edu.au
}

Received 15 September 2011; Accepted 5 December 2011

Academic Editor: Suhn Hee Kim

Copyright (c) 2012 C. Tikellis and M. C. Thomas. This is an open access article distributed under the Creative Commons Attribution License, which permits unrestricted use, distribution, and reproduction in any medium, provided the original work is properly cited.

\begin{abstract}
Angiotensin-converting enzyme 2 (ACE2) shares some homology with angiotensin-converting enzyme (ACE) but is not inhibited by ACE inhibitors. The main role of ACE2 is the degradation of Ang II resulting in the formation of angiotensin 1-7 (Ang 1-7) which opposes the actions of Ang II. Increased Ang II levels are thought to upregulate ACE2 activity, and in ACE2 deficient mice Ang II levels are approximately double that of wild-type mice, whilst Ang 1-7 levels are almost undetectable. Thus, ACE2 plays a crucial role in the RAS because it opposes the actions of Ang II. Consequently, it has a beneficial role in many diseases such as hypertension, diabetes, and cardiovascular disease where its expression is decreased. Not surprisingly, current therapeutic strategies for ACE2 involve augmenting its expression using ACE2 adenoviruses, recombinant ACE2 or compounds in these diseases thereby affording some organ protection.
\end{abstract}

\section{Introduction}

The renin-angiotensin system (RAS) is a signalling pathway that acts as a homeostatic regulator of vascular function [1]. Its systemic actions include the regulation of blood pressure, natriuresis, and blood volume control. However, the RAS also plays an important local role, regulating regional blood flow and controlling trophic responses to a range of stimuli. The RAS is composed of a number of different regulatory components and effector peptides that facilitate the dynamic control of vascular function, in both health and disease (Figure 1). Many of these components have opposing functions to accommodate a rapid but coordinated response to specific triggers. For example, angiotensin I (Ang I) is metabolised by the dipeptide carboxypeptidase, angiotensinconverting enzyme (ACE) to form angiotensin II (Ang II) and Ang II is metabolised by the carboxypeptidase, ACE2, producing the vasodilator, angiotensin ${ }_{(1-7)}$ (Ang 1-7) [2-4]. Historically, ACE and Ang II have been the key focus for clinical interventions targeting the RAS and its pathogenic actions. However, recent studies have also demonstrated the importance of ACE2 in maintaining the balance of the RAS. Indeed, in some settings, and the cardiovascular system in particular, ACE2 may be more important than ACE in regulating local levels of Ang II and Ang 1-7, and therein the balance of RAS activation. For example, we have shown that acquired or genetic deficiency of ACE2 results in increased tissue and circulating levels of Ang II $[5,6]$ and reduced levels of Ang 1-7 [6]. By contrast, Ace KO mice have modestly reduced circulating Ang II, while tissue levels are not significantly modified, possibly as substantial amounts of Ang II are generated by non-ACE pathways, while degradation pathways for Ang II are more limited [7]. This paper will specifically examine the actions of ACE2 in the body and discuss their potential role in health and various disease states.

\section{Angiotensin-Converting Enzyme (ACE2)}

ACE2 is a type 1 integral membrane glycoprotein [8] that is expressed and active in most tissues. The highest expression of ACE2 is observed in the kidney, the endothelium, the lungs, and in the heart $[2,8]$. The extracellular domain of ACE2 enzyme contains a single catalytic metallopeptidase unit that shares $42 \%$ sequence identity and $61 \%$ sequence similarity with the catalytic domain of ACE [2]. However, 


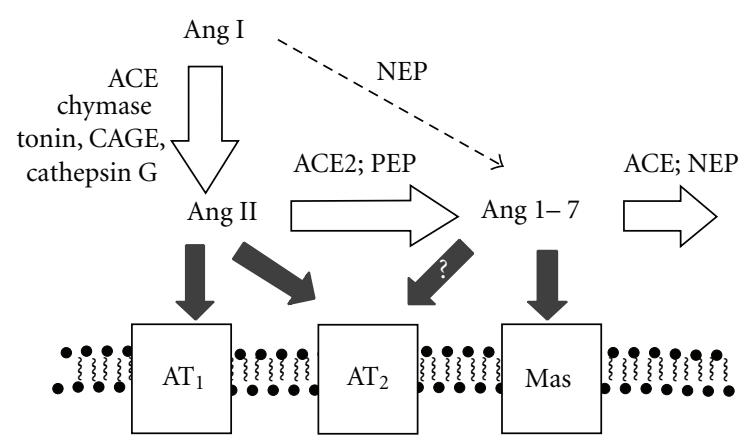

FIGURE 1: Schematic representation of the renin-angiotensin system (RAS) and the key balancing role of ACE2. Abbreviations, ACE: angiotensin-converting enzyme; ACE2: angiotensinconverting enzyme 2; NEP: neprilysin; AT1: Ang II type 1 receptor; AT2: Ang II type 2 receptor; PEP: prolyl endopeptidase; CAGE: chymostatin-sensitive angiotensin II-generating enzyme.

unlike ACE, it functions as a carboxypeptidase, rather than a dipeptidase, and ACE2 activity is not antagonized by conventional ACE inhibitors [4]. The major substrate for ACE2 appears to be (Ang II) [2-4], although other peptides may also be degraded by ACE2, albeit at lower affinity. For example, ACE2 is able to cleave the C-terminal amino acid from angiotensin I, vasoactive bradykinin (1-8), desArg-kallidin (also known as des-Arg ${ }^{10}$ Lys-bradykinin) [2], Apelin-13 and Apelin-36 [9] as well as other possible targets [10]. The noncatalytic C-terminal domain of ACE2 shows $48 \%$ sequence identity with collectrin [11], a protein recently shown to have an important role in neutral amino acid reabsorption from the intestine and the kidney [12]. This is highly consistent with ACE2's actions as a carboxypeptidase, as the removed amino acid then becomes available for reabsorption. The cytoplasmic tail of ACE2 also contains calmodulin-binding sites [13] which may influence shedding of its catalytic ectodomain. In addition, ACE2 has also been associated with integrin function, independent of its angiotensinase activity.

\section{ACE2 and Atherosclerosis}

Abnormal activation of the RAS contributes to the development and progression of atherosclerotic vascular disease [1416]. Independent and additional to the induction of systemic hypertension and vasoconstriction, Ang II has a number of direct proatherosclerotic effects on the vascular wall [17-19], including promoting inflammation [20], endothelial dysfunction [21], oxidative stress, endothelial cell, and vascular smooth muscle cell migration, growth, proliferation [22], and thrombosis. By contrast, the major product of ACE2, Ang 1-7, has a range of anti-inflammatory and antioxidant effects $[23,24]$ that oppose those of Ang II in the vasculature. Indeed, an infusion of Ang 1-7 is able to attenuate vascular dysfunction and atherosclerosis in genetically susceptible apolipoprotein E knockout (apoE KO) mice [25], possibly by increased activation of the Mas receptor and the type 2 angiotensin receptor $\left(\mathrm{AT}_{2}\right)$. It is thought that the balance of

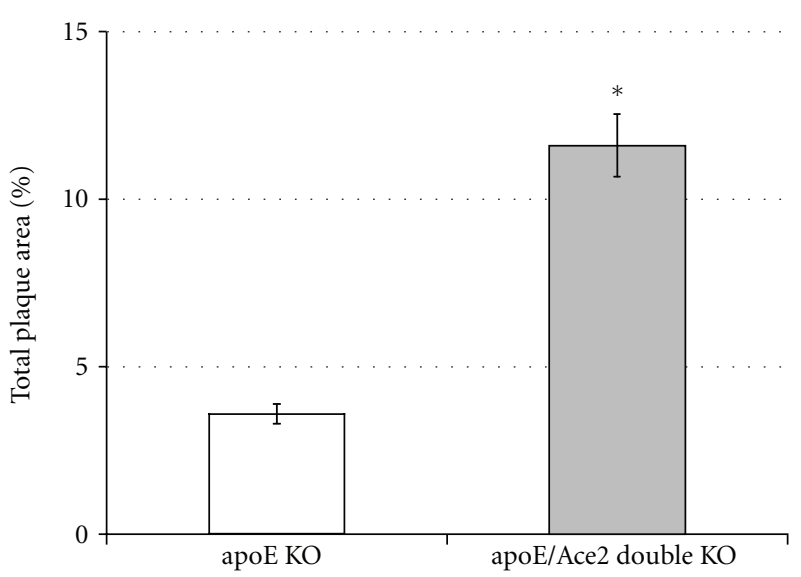

FIGURE 2: Increased plaque area accumulation in the aorta of Apoe/Ace 2 double $\mathrm{KO}$ mice when compared to control Apoe $\mathrm{KO}$ mice [5]. * vs control Apoe KO mice $P<0.05$.

Ang II and Ang 1-7 represents an important driving factor for vascular disease progression. Consequently, ACE2 is also likely to play an important role in atherosclerotic plaque development. Certainly, ACE2 expression is reduced in established atherosclerotic plaques [26] and in proatherosclerotic states, such as diabetes [27]. However, direct evidence for ACE2 in the development and progression of atherosclerotic plaques has only recently become available [5].

We have shown that in apoE KO mice, deficiency of ACE2 is associated with increased plaque accumulation (Figure 2), comparable to that observed following angiotensin II infusion [19]. This possibly relates to an increased proinflammatory responsiveness [5], as leukocyte recruitment and adhesion to the nascent atherosclerotic lesion is generally regarded as one of the first steps toward plaque formation. While a healthy endothelium does not in general support binding of white blood cells, we show that the aortic endothelium of apoE/Ace2 double KO mice shows increased adhesion of labeled leukocytes [5]. In addition, genetic ACE2 deficiency is associated with upregulation of putative mediators of atherogenesis, such as cytokines and adhesion molecules. The role of the RAS in these actions is further emphasized by the finding that RAS blockade is able to prevent atherogenesis in apoE/Ace2 double $\mathrm{KO}$ mice. Such data emphasize the potential utility of ACE2 repletion as a strategy to reduce atherosclerosis, particularly in combination with ACE inhibition and other interventions to reduce activation of the RAS (see below).

\section{ACE2 and Hypertension}

Activation of the RAS is known to be a key mediator of hypertension, and interventions to block RAS activation are the most widely used of all blood pressure lowering agents. The antihypertensive efficacy of these agents is partly mediated by their ability to reduce Ang II or its signalling. However, the antihypertensive effects of conventional RAS blockade are also partly determined by the ability of both ACE inhibitors and angiotensin receptor blockers (ARBs) 
to increase circulating levels of Ang 1-7 [28]. Moreover, inhibiting the vascular actions of Ang 1-7 in spontaneously hypertensive rats (SHRs) receiving RAS blockade, attenuates the antihypertensive response to these agents $[28,29]$. Given that the major source of Ang 1-7 is ACE2, this data suggests that ACE2, consequently influences not only the development of hypertension, but also potentially the response to its treatment. Certainly, ACE2 expression is abnormal in SHRs, in which one genetic component of this phenotype tracks to the Ace2 locus. In addition, ACE2 deficiency is associated with modest systolic hypertension [30], although the mouse genetic background significantly alters the cardiovascular phenotype [30-33]. Ace2 $\mathrm{KO}$ mice also have a heightened hypertensive response to Ang II infusion associated with exaggerated accumulation of Ang II in the kidney [30].

The RAS and ACE2 are also implicated in the pathogenesis of central hypertension. In particular, the rostral ventrolateral medulla (RVLM) is a relay point that provides supraspinal excitatory input to sympathetic preganglionic neurons in the regulation of blood pressure. In the SHRs, ACE2 expression is reduced in the RVLM [34], and persistent overexpression of ACE2 in the RVLM results in a significant attenuation of high blood pressure in this model $[35,36]$. In addition, injections of the ACE2 inhibitor MLN4760 into the nucleus tractus solitarii reduce reflex bradycardia in response to the baroreceptor stimulation in rats [37], suggesting an additional role for central ACE2 in controlling baroreceptor responsiveness.

\section{ACE2 in Heart Failure}

In addition to effects on blood pressure, natriuresis and atherogenesis, the RAS plays a critical pathophysiological role in the maintaining and subsequently subverting cardiac function in the setting of progressive heart failure [38]. The cardiac RAS is upregulated in almost all models of cardiac injury, including volume overload [39], myocardial infarction [40], and heart failure [41]. As in the kidney, RAS upregulation appears to be a homeostatic response to restore cardiac function. For example, Ang II is an inotropic and growth factor for cardiac myocytes, stimulating compensatory hypertrophy [42]. Ang II is also important in left ventricular remodeling following myocardial infarction or with afterload-induced cardiac hypertrophy [43]. However, in the long term such actions lead to progressive functional loss and cardiac fibrosis [42], as the synthesis of extracellular matrix is increased by Ang II [44]. The key role of RAS activation in the development and progression of cardiac failure is supported by findings in a number of different models in which blockade of the RAS was able to attenuate or prevent cardiac damage, independent of blood pressure lowering [45].

In the heart, ACE2 represents the primary pathway for the metabolism of Ang II $[46,47]$. ACE2 deficiency in mice results in early cardiac hypertrophy (Figure 3) [32] and accelerates adverse postmyocardial infarction ventricular remodeling [48]. Furthermore, this appears to be through the activation of the NAPDH oxidase system with the

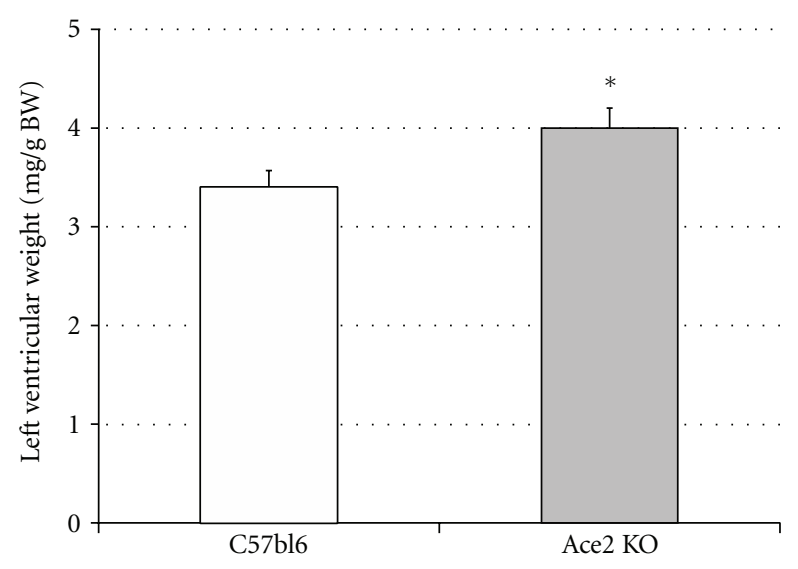

Figure 3: Increased LV mass in Ace2 $\mathrm{KO}$ mice versus C57bl6 mice (unpublished data). ${ }^{*}$ vs control C57Bl6 mice, $P<0.05$.

p47(phox) subunit playing a critical role [49]. In some, but not all models, ACE2 deficiency also results in progressive cardiac fibrosis with aging and/or cardiac pressure overload $[33,50,51]$. Again, these changes are reversed following treatment with $\mathrm{ACE}$ inhibitors or $\mathrm{AT}_{1}$ receptor blockers $[33,50,51]$ suggesting that the balance of ACE and ACE2 in the heart is an important driving factor for progressive cardiac disease.

\section{ACE2 and Chronic Kidney Disease (CKD)}

The RAS also plays an important role in renal physiology and pathophysiology. In the adult kidney [2], ACE2 is predominantly expressed in the proximal tubule at the luminal brush border. Despite the presence of unopposed ACE activity and elevated Ang II levels, both kidney function and renal development are normal in the Ace 2 knockout mouse [33]. By comparison, ACE, angiotensinogen, and AT1 receptor deficiency results in a number of alterations in kidney morphology [52]. This suggests that, at least in the healthy state, ACE2 may have a limited role in regulating renal development. However, the actions of ACE2 appear to come into its own in states of RAS activation. This is much like Ang 1-7, its major product, which shows very limited renal effects in the healthy state but profound benefits in the diabetic kidney and other states associated with renal damage and activation $[10,53]$. For example, ACE2 deficient mice have been reported to show increased age-related glomerulosclerosis in susceptible mouse models [54] and enhanced renal Ang II-induced renal oxidative stress, resulting in greater renal injury [55]. Similarly, in the diabetic kidney, downregulation of tubular ACE2 (Figure 4) [27] is associated with albuminuria or tubular injury, while further inhibition of ACE2 results in augmented renal damage [56, 57]. Indeed, in most forms of CKD, including diabetes, expression of ACE2 has been reported to be reduced in tubules. However, some studies have reported that glomerular ACE2 expression may be increased in human kidney disease [58]. It is possible that this differential expression pattern of glomerular and 


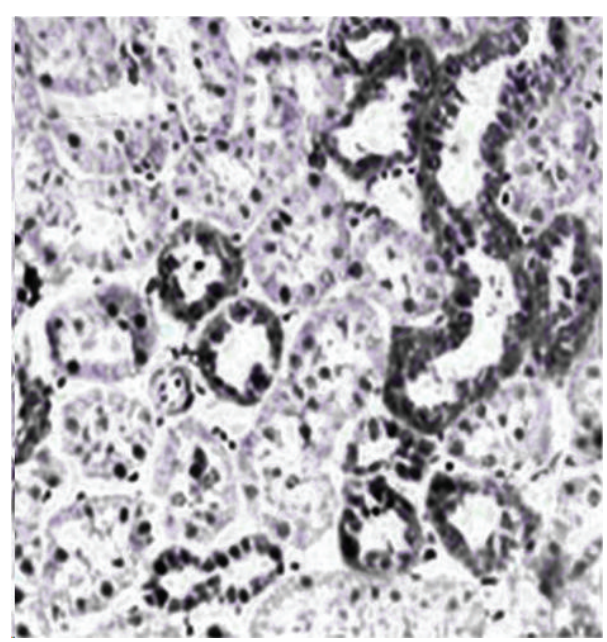

(a)

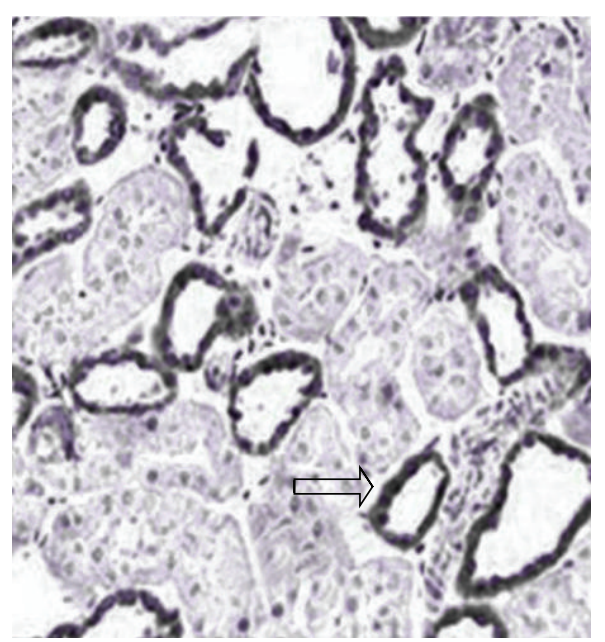

(b)

Figure 4: Reduced ACE2 expression (arrows) in renal cortical tubules of diabetic mice (b) when compared to control mice (a) [27].

tubular ACE2 is an important determinant for progressive renal disease.

\section{ACE2 and the Lung}

RAS activity is intrinsically high in the lung, which is a major source of ACE and therefore a major site of systemic Ang II synthesis. ACE2 is also highly expressed in the lung. Pulmonary ACE2 appears to have a role in regulating the balance of circulating Ang II/Ang 1-7 levels. Ang II induces pulmonary vasoconstriction in response to hypoxia, which is important in preventing shunting in patients with pneumonia or lung injury [59]. Locally increased Ang II production also triggers increasing vascular permeability facilitating pulmonary edema [60]. In Acute respiratory distress syndrome (ARDS), the RAS appears crucial in maintaining oxygenation, possibly as widespread lung injury would otherwise result in complete pulmonary shutdown. Certainly in ARDS models, ACE2 knockout mice displayed more severe symptoms of this disease compared with wildtype mice [60] while overexpression appears protective (see below). Interestingly, ACE2 protein also appears to be the entry-point receptor for the severe acute respiratory syndrome (SARS) coronavirus $[61,62]$.

\section{Replenishing ACE2 as a Potential Therapeutic}

Given the key role of ACE2, degrading Ang II and generating Ang 1-7, a number of studies have explored its potential as a treatment strategy using human recombinant ACE2 (rhACE2) or adenoviral (Ad)-ACE2 in animal disease models. For example, overexpression of ACE2 in human endothelial cells attenuates Ang II-induced oxidative stress and subsequent increase in monocyte adhesion [63]. Similarly, in rabbits, a recombinant ACE2 expressing vector stabilized atherosclerotic plaques induced by balloon injury to the abdominal aorta [64]. Treatment with a lentiviral vector containing ACE2 resulted in lower blood pressure in hypertensive mice $[65,66]$ or following an Ang II infusion [67]. Strategies to upregulate or replenish ACE2 are thought to be beneficial in diabetic nephropathy. For example, in diabetes the replenishment of ACE2 with rhACE2 in a mouse model of type 1 diabetes attenuated diabetic kidney injury as well as reducing in blood pressure [68]. The use of (Ad)ACE2 has had similar beneficial effects in streptozotocininduced diabetes, where it was shown to attenuate glomerular mesangial cell proliferation, blood pressure, oxidative stress, and fibrosis [69].

In contrast to these studies, the potential utility of ACE2 supplementation in cardiac disease remains controversial. The expression of ACE2 in the failing human heart is generally increased [70-72], consistent with the finding of elevated levels of Ang 1-7 in the same setting [73]. More importantly, overexpression of ACE2 in cardiac myocytes resulted in conduction disturbances by 2 weeks of age, ultimately leading to lethal ventricular arrhythmias and severe fibrosis $[74,75]$. This may be because ACE2 is not normally expressed in high levels in myocytes, although it is present in the endocardium and other cardiac cells. However, other studies using transgenic overexpression of cardiac ACE2 have demonstrated partial protection in the heart from ischemiainduced heart failure [76]. Indeed, more recent studies using rhACE2 have shown beneficial cardiac effects [77]. However, the indication for ACE2 that appears most likely to be first tested in the clinic is the treatment of ARDS. In murine models, treatment with catalytically active recombinant ACE2 protein improved the symptoms of acute lung injury in wild-type mice as well as in ACE2 knockout mice [60]. Clinical trials in this often fatal condition are now underway.

Perhaps, the most clinically interesting, however, is the potential for rACE2 to augment the vasculoprotective effects of ACE inhibition or ARBs, in the millions of patients that take these agents, worldwide. In theory, this would be achieved by preventing feedback escape for RAS blockade or enhancing the generation of Ang 1-7, and subsequent 
signaling through the Mas receptor and or $\mathrm{AT}_{2}$ receptor. Certainly, ACE2 inhibition attenuates the effects of RAS blockade, both in vitro [78] and in vivo [6]. But could rACE2 make the response to conventional RAS blockade more effective or durable? The problem is that conventional RAS blockade is highly effective in animal models of vascular and renal disease, meaning that it is difficult to explore the potential for further improvements. However, chronic intravenous infusion of ANG-(1-7), or the nonpeptide mas receptor agonist, AVE-0991, are able to improve salt-induced suppression of endothelium-dependent vasodilatation in the mesenteric arteries of male Sprague-Dawley rats, and these actions are not modified by the angiotensin receptor blocker, losartan [79], suggesting that the effects of enhancing the Ang 1-7 mas axis may be beneficial, even in the setting of conventional RAS blockade. Although it enhances the generation of Ang 1-7, whether rACE2 can also provide synergistic benefits, remains to be established.

\section{ACE2 Augmenters: A New Kind of Intervention}

Rather than providing exogenous ACE2, an alternative approach for augmenting ACE2 has been to increase its endogenous expression. For example, in hypertensive SHRs, all-trans retinoic acid, which increases ACE2 expression, lowers blood pressure levels, and prevents vascular damage [80]. Unfortunately retinoic acid has broader actions that make its potential utility as a therapeutic limited. However, compounds that increase activity of ACE2 could also be beneficial as a treatment in conditions where ACE2 activity is decreased. One exemplar is xanthenone (XNT). This molecule was selected following structure-based screening on compounds that would stabilize the activated form of ACE2, thereby enhancing its catalytic efficacy [81]. In experimental studies, this compound has been shown to enhance ACE2 activity in a dose-dependent manner and significantly decreased blood pressure in both SHRs rats and wild-type WKY rats [81]. Furthermore, improvements in cardiac function and reversal of myocardial, perivascular, and renal fibrosis in the SHRs were also observed [81, 82]. $\mathrm{XNT}$ has also shown promise in treating pulmonary hypertension $(\mathrm{PH})$. For example, in a rat model of $\mathrm{PH}$, treatment with XNT was shown to reduce elevated right ventricular systolic pressure, right ventricular hypertrophy, increased pulmonary vessel wall thickness, and interstitial fibrosis [83]. In a model of thrombus formation using SHRs and WKY rats, XNT has also shown antithrombotic action, reducing platelet attachment, and reducing thrombus formation [84]. This compound will not come to clinical trials because of issues of solubility that restrict its formulation. However, other drugs of the same class may prove more suitable.

\section{Conclusion}

ACE2 is an integral component of the RAS. It is highly expressed in the vasculature, the kidney, lungs, and heart where its actions on peptide signals balance and offset those of ACE. Its actions appear critical in a variety of disease states, including hypertension, diabetes, ageing, renal impairment, and cardiovascular disease. ACE2 deficiency leads to modest physiological changes. However, in states of RAS activation, the loss of ACE2 appears far more important in the development and progression of disease. By contrast, augmentation of ACE2 expression, either directly with recombinant ACE2 or indirectly via agonists like XNT, may have important benefits relevant in the treatment of a range of conditions.

\section{Acknowledgments}

Research in the field of ACE2 has been supported by grants from JDRF, NHF, and Australian NHMRC. Dr. C. Tikellis is supported by a JDRF CDA fellowship.

\section{References}

[1] S. D. Crowley, S. B. Gurley, M. I. Oliverio et al., "Distinct roles for the kidney and systemic tissues in blood pressure regulation by the renin-angiotensin system," The Journal of Clinical Investigation, vol. 115, no. 4, pp. 1092-1099, 2005.

[2] M. Donoghue, F. Hsieh, E. Baronas et al., "A novel angiotensin-converting enzyme-related carboxypeptidase (ACE2) converts angiotensin I to angiotensin 1-9," Circulation Research, vol. 87, no. 5, pp. E1-E9, 2000.

[3] A. J. Turner and N. M. Hooper, "The angiotensin-converting enzyme gene family: genomics and pharmacology," Trends in Pharmacological Sciences, vol. 23, no. 4, pp. 177-183, 2002.

[4] G. I. Rice, D. A. Thomas, P. J. Grant, A. J. Turner, and N. M. Hooper, "Evaluation of angiotensin-converting enzyme (ACE), its homologue ACE2 and neprilysin in angiotensin peptide metabolism," Biochemical Journal, vol. 383, part 1, pp. 45-51, 2004.

[5] M. C. Thomas, R. J. Pickering, D. Tsorotes et al., "Genetic Ace2 deficiency accentuates vascular inflammation and atherosclerosis in the ApoE knockout mouse," Circulation Research, vol. 107, no. 7, pp. 888-897, 2010.

[6] C. Tikellis, K. Bialkowski, J. Pete et al., "ACE2 deficiency modifies renoprotection afforded by ACE inhibition in experimental diabetes," Diabetes, vol. 57, no. 4, pp. 1018-1025, 2008.

[7] C. C. Wei, B. Tian, G. Perry et al., "Differential ANG II generation in plasma and tissue of mice with decreased expression of the ACE gene," American Journal of Physiology, vol. 282, no. 6, pp. H2254-H2258, 2002.

[8] S. R. Tipnis, N. M. Hooper, R. Hyde, E. Karran, G. Christie, and A. J. Turner, "A human homolog of angiotensinconverting enzyme: cloning and functional expression as a captopril-insensitive carboxypeptidase," The Journal of Biological Chemistry, vol. 275, no. 43, pp. 33238-33243, 2000.

[9] K. Kuba, L. Zhang, Y. Imai et al., "Impaired heart contractility in Apelin gene-deficient mice associated with aging and pressure overload," Circulation Research, vol. 101, no. 4, pp. e32-e42, 2007.

[10] C. Vickers, P. Hales, V. Kaushik et al., "Hydrolysis of biological peptides by human angiotensin-converting enzyme-related carboxypeptidase," The Journal of Biological Chemistry, vol. 277, no. 17, pp. 14838-14843, 2002.

[11] H. Zhang, J. Wada, K. Hida et al., "Collectrin, a collecting duct-specific transmembrane glycoprotein, is a novel homolog of ACE2 and is developmentally regulated in embryonic 
kidneys," The Journal of Biological Chemistry, vol. 276, no. 20, pp. 17132-17139, 2001.

[12] S. Kowalczuk, A. Bröer, N. Tietze, J. M. Vanslambrouck, J. E. J. Rasko, and S. Bröer, "A protein complex in the brush-border membrane explains a Hartnup disorder allele," The FASEB Journal, vol. 22, no. 8, pp. 2880-2887, 2008.

[13] D. W. Lambert, N. E. Clarke, N. M. Hooper, and A. J. Turner, "Calmodulin interacts with angiotensin-converting enzyme-2 (ACE2) and inhibits shedding of its ectodomain," FEBS Letters, vol. 582, no. 2, pp. 385-390, 2008.

[14] C. I. Johnston, "Tissue angiotensin converting enzyme in cardiac and vascular hypertrophy, repair, and remodeling," Hypertension, vol. 23, no. 2, pp. 258-268, 1994.

[15] Min Ae Lee, M. Bohm, M. Paul, and D. Ganten, "Tissue reninangiotensin systems: their role in cardiovascular disease," Circulation, vol. 87, no. 5, pp. IV7-IV13, 1993.

[16] D. S. Jacoby and D. J. Rader, "Renin-angiotensin system and atherothrombotic disease: from genes to treatment," Archives of Internal Medicine, vol. 163, no. 10, pp. 1155-1164, 2003.

[17] R. Candido, K. A. Jandeleit-Dahm, Z. Cao et al., "Prevention of accelerated atherosclerosis by angiotensin-converting enzyme inhibition in diabetic apolipoprotein E-deficient mice," Circulation, vol. 106, no. 2, pp. 246-253, 2002.

[18] R. Candido, T. J. Allen, M. Lassila et al., "Irbesartan but not amlodipine suppresses diabetes-associated atherosclerosis," Circulation, vol. 109, no. 12, pp. 1536-1542, 2004.

[19] L. A. Cassis, M. Gupte, S. Thayer et al., "ANG II infusion promotes abdominal aortic aneurysms independent of increased blood pressure in hypercholesterolemic mice," American Journal of Physiology, vol. 296, no. 5, pp. H1660-H1665, 2009.

[20] X. L. Chen, P. E. Tummala, M. T. Olbrych, R. W. Alexander, and R. M. Medford, "Angiotensin II induces monocyte chemoattractant protein-1 gene expression in rat vascular smooth muscle cells," Circulation Research, vol. 83, no. 9, pp. 952-959, 1998.

[21] A. E. Loot, J. G. Schreiber, B. Fisslthaler, and I. Fleming, "Angiotensin II impairs endothelial function via tyrosine phosphorylation of the endothelial nitric oxide synthase," Journal of Experimental Medicine, vol. 206, no. 13, pp. 28892896, 2009.

[22] M. J. A. P. Daemen, D. M. Lombardi, F. T. Bosman, and S. M. Schwartz, "Angiotensin II induces smooth muscle cell proliferation in the normal and injured rat arterial wall," Circulation Research, vol. 68, no. 2, pp. 450-456, 1991.

[23] J. L. Probstfield and K. D. O'Brien, "Progression of cardiovascular damage: the role of renin-angiotensin system blockade," American Journal of Cardiology, vol. 105, no. 1, supplement, pp. 10A-20A, 2010.

[24] C. M. Ferrario, A. J. Trask, and J. A. Jessup, "Advances in biochemical and functional roles of angiotensin-converting enzyme 2 and angiotensin-(1-7) in regulation of cardiovascular function," American Journal of Physiology, vol. 289, no. 6, pp. H2281-H2290, 2005.

[25] S. Tesanovic, A. Vinh, T. A. Gaspari, D. Casley, and R. E. Widdop, "Vasoprotective and atheroprotective effects of angiotensin (1-7) in apolipoprotein E-deficient mice," Arteriosclerosis, Thrombosis, and Vascular Biology, vol. 30, no. 8, pp. 1606-1613, 2010.

[26] J. C. Sluimer, J. M. Gasc, I. Hamming et al., "Angiotensinconverting enzyme 2 (ACE2) expression and activity in human carotid atherosclerotic lesions," The Journal of Pathology, vol. 215, no. 3, pp. 273-279, 2008.
[27] C. Tikellis, C. I. Johnston, J. M. Forbes et al., "Characterization of renal angiotensin-converting enzyme 2 in diabetic nephropathy," Hypertension, vol. 41, no. 3, pp. 392-397, 2003.

[28] L. Stanziola, L. J. Greene, and R. A. S. Santos, "Effect of chronic angiotensin converting enzyme inhibition on angiotensin I and bradykinin metabolism in rats," American Journal of Hypertension, vol. 12, no. 10, part 1, pp. 1021-1029, 1999.

[29] I. F. Benter, M. H. M. Yousif, F. M. Al-Saleh, R. Raghupathy, M. C. Chappell, and D. I. Diz, "Angiotensin-(1-7) blockade attenuates captopril- or hydralazine-induced cardiovascular protection in spontaneously hypertensive rats treated with NG-nitro-l-arginine methyl ester," Journal of Cardiovascular Pharmacology, vol. 57, no. 5, pp. 559-567, 2011.

[30] S. B. Gurley, A. Allred, T. H. Le et al., "Altered blood pressure responses and normal cardiac phenotype in ACE2-null mice," The Journal of Clinical Investigation, vol. 116, no. 8, pp. 22182225, 2006.

[31] S. B. Gurley and T. M. Coffman, "Angiotensin-converting enzyme 2 gene targeting studies in mice: mixed messages," Experimental Physiology, vol. 93, no. 5, pp. 538-542, 2008.

[32] G. Y. Oudit, Z. Kassiri, M. P. Patel et al., "Angiotensin IImediated oxidative stress and inflammation mediate the agedependent cardiomyopathy in ACE2 null mice," Cardiovascular Research, vol. 75, no. 1, pp. 29-39, 2007.

[33] M. A. Crackower, R. Sarao, G. Y. Oudit et al., "Angiotensinconverting enzyme 2 is an essential regulator of heart function," Nature, vol. 417, no. 6891, pp. 822-828, 2002.

[34] M. Yamazato, Y. Yamazato, C. Sun, C. Diez-Freire, and M. K. Raizada, "Overexpression of angiotensin-converting enzyme 2 in the rostral ventrolateral medulla causes long-term decrease in blood pressure in the spontaneously hypertensive rats," Hypertension, vol. 49, no. 4, pp. 926-931, 2007.

[35] Y. Feng, H. Xia, Y. Cai et al., "Brain-selective overexpression of human angiotensin-converting enzyme type 2 attenuates neurogenic hypertension," Circulation Research, vol. 106, no. 2, pp. 373-382, 2010.

[36] Y. Feng, X. Yue, H. Xia et al., "Angiotensin-converting enzyme 2 overexpression in the subfornical organ prevents the angiotensin II-mediated pressor and drinking responses and is associated with angiotensin II type 1 receptor downregulation," Circulation Research, vol. 102, no. 6, pp. 729-736, 2008.

[37] D. I. Diz, M. A. Garcia-Espinosa, S. Gegick et al., "Injections of angiotensin-converting enzyme 2 inhibitor MLN4760 into nucleus tractus solitarii reduce baroreceptor reflex sensitivity for heart rate control in rats," Experimental Physiology, vol. 93, no. 5, pp. 694-700, 2008.

[38] F. Pieruzzi, Z. A. Abassi, and H. R. Keiser, "Expression of renin-angiotensin system components in the heart, kidneys, and lungs of rats with experimental heart failure," Circulation, vol. 92, no. 10, pp. 3105-3112, 1995.

[39] M. Ruzicka, F. W. Keeley, and F. H. H. Leenen, "The reninangiotensin system and volume overload-induced changes in cardiac collagen and elastin," Circulation, vol. 90, no. 4, pp. 1989-1996, 1994.

[40] A. T. Hirsch, C. E. Talsness, H. Schunkert, M. Paul, and V. J. Dzau, "Tissue-specific activation of cardiac angiotensin converting enzyme in experimental heart failure," Circulation Research, vol. 69, no. 2, pp. 475-482, 1991.

[41] S. Hokimoto, H. Yasue, K. Fujimoto et al., "Expression of angiotensin-converting enzyme in remaining viable myocytes of human ventricles after myocardial infarction," Circulation, vol. 94, no. 7, pp. 1513-1518, 1996. 
[42] J. I. Sadoshima, Y. Xu, H. S. Slayter, and S. Izumo, "Autocrine release of angiotensin II mediates stretch-induced hypertrophy of cardiac myocytes in vitro," Cell, vol. 75, no. 5, pp. 977984, 1993.

[43] M. Kakishita, K. Nakamura, M. Asanuma et al., "Direct evidence for increased hydroxyl radicals in angiotensin IIinduced cardiac hypertrophy through angiotensin II type 1a receptor," Journal of Cardiovascular Pharmacology, vol. 42, supplement 1, pp. S67-S70, 2003.

[44] K. T. Weber, Y. Sun, and E. Guarda, "Structural remodeling in hypertensive heart disease and the role of hormones," Hypertension, vol. 23, no. 6, pp. 869-877, 1994.

[45] M. A. Pfeffer, E. Braunwald, L. A. Moye et al., "Effect of captopril on mortality and morbidity in patients with left ventricular dysfunction after myocardial infarction-results of the survival and ventricular enlargement trial," The New England Journal of Medicine, vol. 327, no. 10, pp. 669-677, 1992.

[46] P. J. Garabelli, J. G. Modrall, J. M. Penninger, C. M. Ferrario, and M. C. Chappell, "Distinct roles for angiotensin-converting enzyme 2 and carboxypeptidase A in the processing of angiotensins within the murine heart," Experimental Physiology, vol. 93, no. 5, pp. 613-621, 2008.

[47] J. A. Stewart Jr., E. Lazartigues, and P. A. Lucchesi, "The angiotensin converting enzyme 2/Ang-(1-7) axis in the heart: a role for mas communication?" Circulation Research, vol. 103, no. 11, pp. 1197-1199, 2008.

[48] Z. Kassiri, J. Zhong, D. Guo et al., "Loss of angiotensinconverting enzyme 2 accelerates maladaptive left ventricular remodeling in response to myocardial infarction," Circulation, vol. 2, no. 5, pp. 446-455, 2009.

[49] S. Bodiga, J. C. Zhong, W. Wang et al., "Enhanced susceptibility to biomechanical stress in ACE2 null mice is prevented by loss of the p47phox NADPH oxidase subunit," Cardiovascular Research, vol. 91, no. 1, pp. 151-161, 2011.

[50] K. Yamamoto, M. Ohishi, T. Katsuya et al., "Deletion of angiotensin-converting enzyme 2 accelerates pressure overload-induced cardiac dysfunction by increasing local angiotensin II," Hypertension, vol. 47, no. 4, pp. 718-726, 2006.

[51] K. Nakamura, N. Koibuchi, H. Nishimatsu et al., "Candesartan ameliorates cardiac dysfunction observed in angiotensinconverting enzyme 2-deficient mice," Hypertension Research, vol. 31, no. 10, pp. 1953-1961, 2008.

[52] T. N. Doan, N. Gletsu, J. Cole, and K. E. Bernstein, "Genetic manipulation of the renin-angiotensin system," Current Opinion in Nephrology and Hypertension, vol. 10, no. 4, pp. 483491, 2001.

[53] N. Li, J. Zimpelmann, K. Cheng, J. A. Wilkins, and K. D. Burns, "The role of angiotensin converting enzyme 2 in the generation of angiotensin 1-7 by rat proximal tubules," American Journal of Physiology, vol. 288, no. 2, pp. F353-F362, 2005.

[54] G. Y. Oudit, A. M. Herzenberg, Z. Kassiri et al., "Loss of angiotensin-converting enzyme-2 leads to the late development of angiotensin II-dependent glomerulosclerosis," American Journal of Pathology, vol. 168, no. 6, pp. 1808-1820, 2006.

[55] J. Zhong, D. Guo, C. B. Chen et al., "Prevention of angiotensin II-mediated renal oxidative stress, inflammation, and fibrosis by angiotensin-converting enzyme 2," Hypertension, vol. 57, no. 2, pp. 314-322, 2010.

[56] M. J. Soler, J. Wysocki, M. Ye, J. Lloveras, Y. Kanwar, and D. Batlle, "ACE2 inhibition worsens glomerular injury in association with increased ACE expression in streptozotocininduced diabetic mice," Kidney International, vol. 72, no. 5, pp. 614-623, 2007.
[57] D. W. Wong, G. Y. Oudit, H. Reich et al., "Loss of Angiotensin-converting enzyme-2 (Ace2) accelerates diabetic kidney injury," American Journal of Pathology, vol. 171, no. 2, pp. 438$451,2007$.

[58] A. T. Lely, I. Hamming, H. van Goor, and G. J. Navis, "Renal ACE2 expression in human kidney disease," The Journal of Pathology, vol. 204, no. 5, pp. 587-593, 2004.

[59] D. G. Kiely, R. I. Cargill, N. M. Wheeldon, W. J. Coutie, and B. J. Lipworth, "Haemodynamic and endocrine effects of type 1 angiotensin II receptor blockade in patients with hypoxaemic cor pulmonale," Cardiovascular Research, vol. 33, no. 1, pp. 201-208, 1997.

[60] Y. Imai, K. Kuba, S. Rao et al., "Angiotensin-converting enzyme 2 protects from severe acute lung failure," Nature, vol. 436, no. 7047, pp. 112-116, 2005.

[61] W. Li, M. J. Moore, N. Vasllieva et al., "Angiotensin-converting enzyme 2 is a functional receptor for the SARS coronavirus," Nature, vol. 426, no. 6965, pp. 450-454, 2003.

[62] K. Kuba, Y. Imai, S. Rao et al., "A crucial role of angiotensin converting enzyme 2 (ACE2) in SARS coronavirus-induced lung injury," Nature Medicine, vol. 11, no. 8, pp. 875-879, 2005.

[63] F. Lovren, Y. Pan, A. Quan et al., "Angiotensin converting enzyme-2 confers endothelial protection and attenuates atherosclerosis," American Journal of Physiology, vol. 295, no. 4, pp. H1377-H1384, 2008.

[64] B. Dong, C. Zhang, J. B. Feng et al., "Overexpression of ACE2 enhances plaque stability in a rabbit model of atherosclerosis," Arteriosclerosis, Thrombosis, and Vascular Biology, vol. 28, no. 7, pp. 1270-1276, 2008.

[65] C. Díez-Freire, J. Vázquez, M. F. Correa De Adjounian et al., "ACE2 gene transfer attenuates hypertension-linked pathophysiological changes in the SHR," Physiological Genomics, vol. 27, no. 1, pp. 12-19, 2006.

[66] B. Rentzsch, M. Todiras, R. Iliescu et al., "Transgenic angiotensin-converting enzyme 2 overexpression in vessels of SHRSP rats reduces blood pressure and improves endothelial function," Hypertension, vol. 52, no. 5, pp. 967-973, 2008.

[67] J. Wysocki, M. Ye, E. Rodriguez et al., "Targeting the degradation of angiotensin II with recombinant angiotensinconverting enzyme 2: prevention of angiotensin II-dependent hypertension," Hypertension, vol. 55, no. 1, pp. 90-98, 2010.

[68] G. Y. Oudit, G. C. Liu, J. Zhong et al., "Human recombinant ACE2 reduces the progression of diabetic nephropathy," Diabetes, vol. 59, no. 2, pp. 529-538, 2010.

[69] C. X. Liu, Q. Hu, Y. Wang et al., “Angiotensin-converting enzyme (ACE) 2 overexpression ameliorates glomerular injury in a rat model of diabetic nephropathy: a comparison with ACE inhibition," Molecular Medicine, vol. 17, no. 1-2, pp. 59-69, 2011.

[70] A. B. Goulter, M. Avella, K. M. Botham, and J. Elliott, "Chylomicron-remnant-like particles inhibit the basal nitric oxide pathway in porcine coronary artery and aortic endothelial cells," Clinical Science, vol. 105, no. 3, pp. 363-371, 2003.

[71] R. Studer, H. Reinecke, B. Muller, J. Holtz, H. Just, and H. Drexler, "Increased angiotensin-I converting enzyme gene expression in the failing human heart. Quantification by competitive RNA polymerase chain reaction," The Journal of Clinical Investigation, vol. 94, no. 1, pp. 301-310, 1994.

[72] L. S. Zisman, R. S. Keller, B. Weaver et al., "Increased angiotensin-(1-7)-forming activity in failing human heart ventricles: evidence for upregulation of the angiotensinconverting enzyme homologue ACE2," Circulation, vol. 108, no. 14, pp. 1707-1712, 2003. 
[73] C. Communal, M. Singh, B. Menon, Z. Xie, W. S. Colucci, and K. Singh, " $\beta 1$ integrins expression in adult rat ventricular myocytes and its role in the regulation of $\beta$-adrenergic receptorstimulated apoptosis," Journal of Cellular Biochemistry, vol. 89, no. 2, pp. 381-388, 2003.

[74] M. Donoghue, H. Wakimoto, C. T. Maguire et al., "Heart block, ventricular tachycardia, and sudden death in ACE2 transgenic mice with downregulated connexins," Journal of Molecular and Cellular Cardiology, vol. 35, no. 9, pp. 10431053, 2003.

[75] R. Masson, S. A. Nicklin, M. A. Craig et al., "Onset of experimental severe cardiac fibrosis is mediated by overexpression of Angiotensin-converting enzyme 2," Hypertension, vol. 53, no. 4, pp. 694-700, 2009.

[76] S. Der Sarkissian, J. L. Grobe, L. Yuan et al., "Cardiac overexpression of angiotensin converting enzyme 2 protects the heart from ischemia-induced pathophysiology," Hypertension, vol. 51, no. 3, pp. 712-718, 2008.

[77] J. Zhong, R. Basu, D. Guo et al., "Angiotensin-converting enzyme 2 suppresses pathological hypertrophy, myocardial fibrosis, and cardiac dysfunction," Circulation, vol. 122, no. 7, pp. 717-728, 2010.

[78] N. Hayashi, K. Yamamoto, M. Ohishi et al., "The counterregulating role of ACE2 and ACE2-mediated angiotensin 1-7 signaling against angiotensin II stimulation in vascular cells," Hypertension Research, vol. 33, no. 11, pp. 1182-1185, 2010.

[79] G. Raffai, M. J. Durand, and J. H. Lombard, "Acute and chronic angiotensin-(1-7) restores vasodilation and reduces oxidative stress in mesenteric arteries of salt-fed rats," American Journal of Physiology, vol. 301, no. 4, pp. H1341-H1352, 2011.

[80] J. C. Zhong, D. Y. Huang, Y. M. Yang et al., "Upregulation of angiotensin-converting enzyme 2 by all-trans retinoic acid in spontaneously hypertensive rats," Hypertension, vol. 44, no. 6, pp. 907-912, 2004.

[81] J. A. Hernández Prada, A. J. Ferreira, M. J. Katovich et al., "Structure-based identification of small-molecule angiotensin-converting enzyme 2 activators as novel antihypertensive agents," Hypertension, vol. 51, no. 5, pp. 1312-1317, 2008.

[82] A. J. Ferreira, V. Shenoy, Y. Qi et al., "Angiotensin-converting enzyme 2 activation protects against hypertension-induced cardiac fibrosis involving extracellular signal-regulated kinases," Experimental Physiology, vol. 96, no. 3, pp. 287-294, 2011.

[83] A. J. Ferreira, V. Shenoy, Y. Yamazato et al., "Evidence for angiotensin-converting enzyme 2 as a therapeutic target for the prevention of pulmonary hypertension," American Journal of Respiratory and Critical Care Medicine, vol. 179, no. 11, pp. 1048-1054, 2009.

[84] R. A. Fraga-Silva, B. S. Sorg, M. Wankhede et al., "ACE2 activation promotes antithrombotic activity," Molecular Medicine, vol. 16, no. 5-6, pp. 210-215, 2010. 

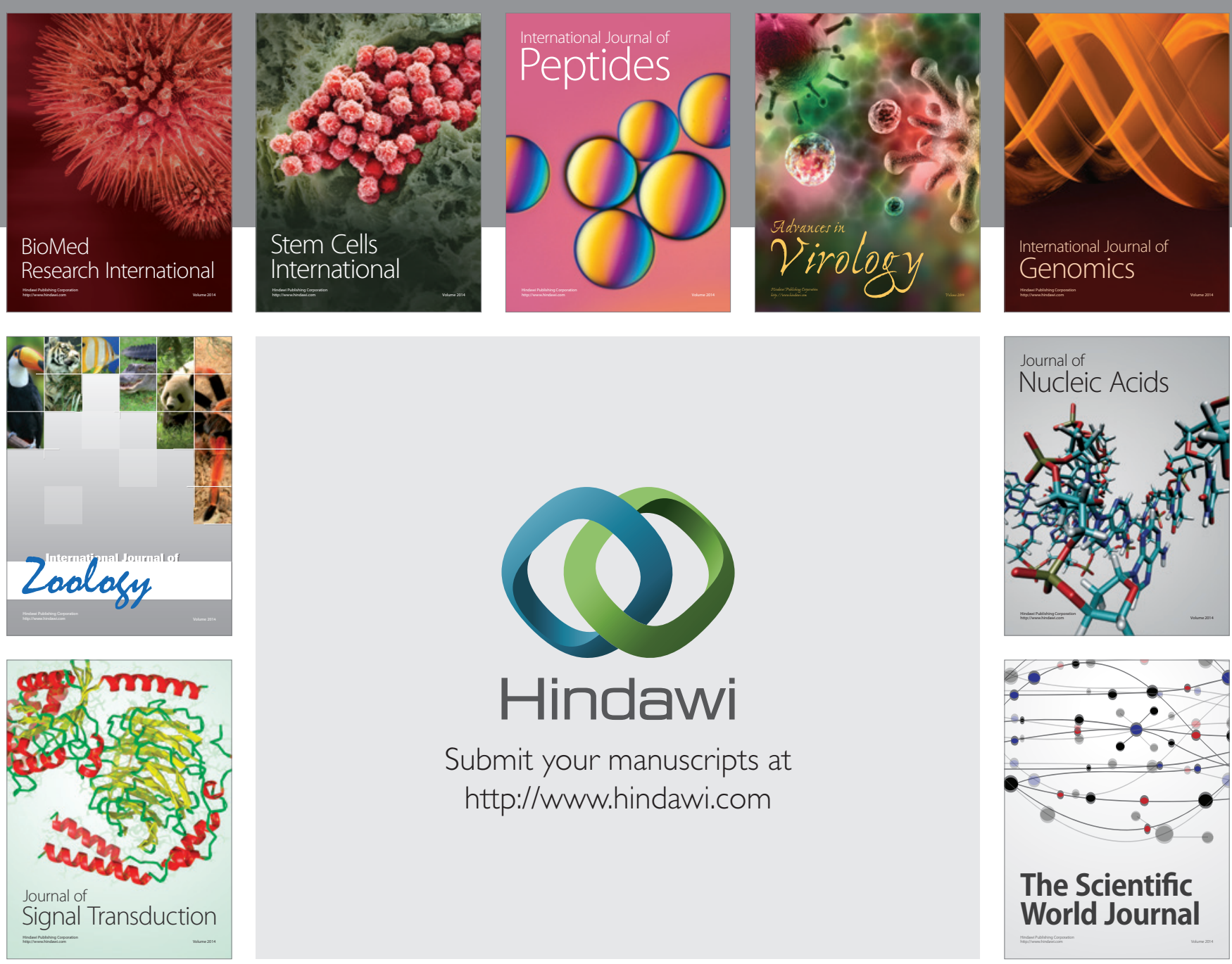

Submit your manuscripts at

http://www.hindawi.com
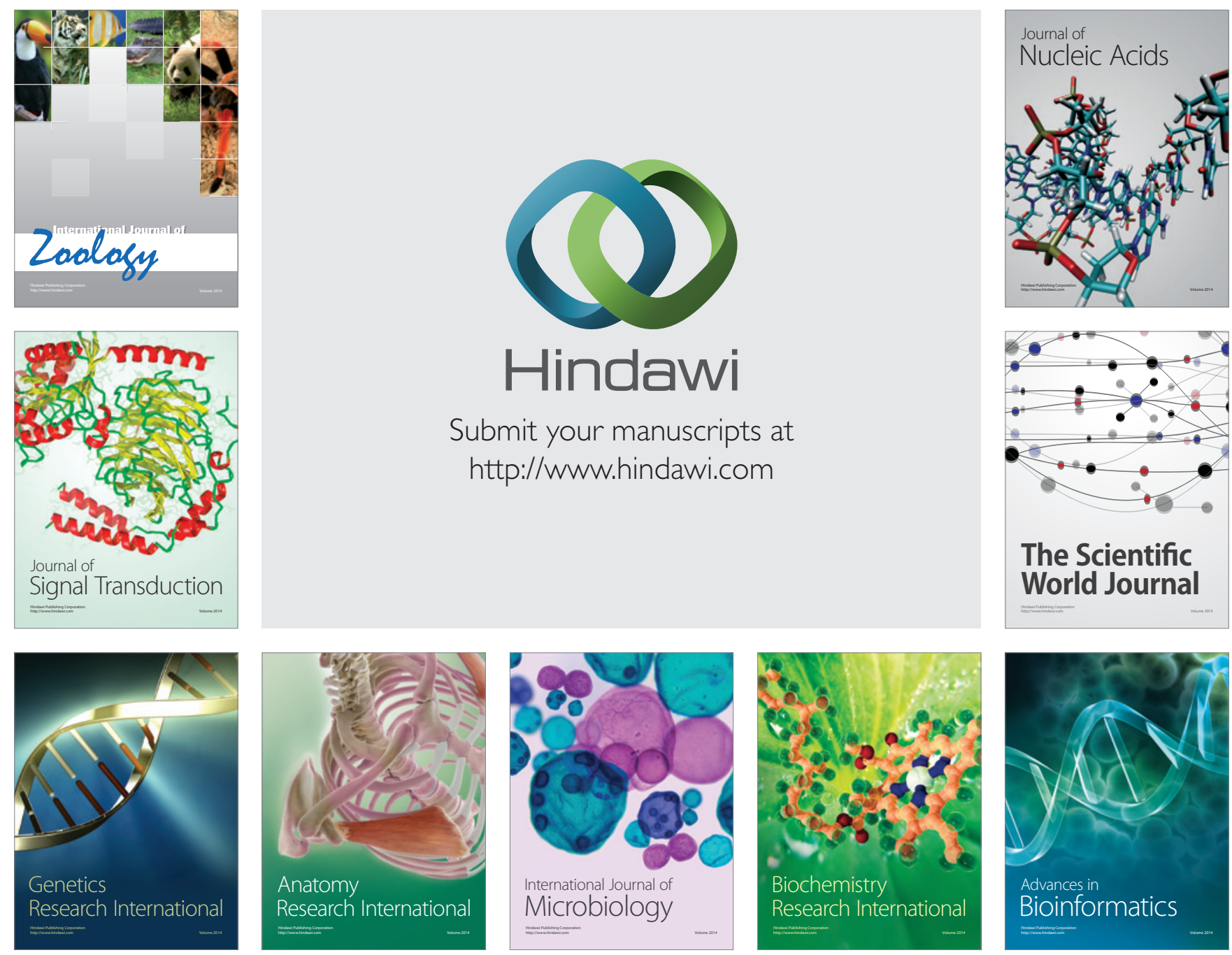

The Scientific World Journal
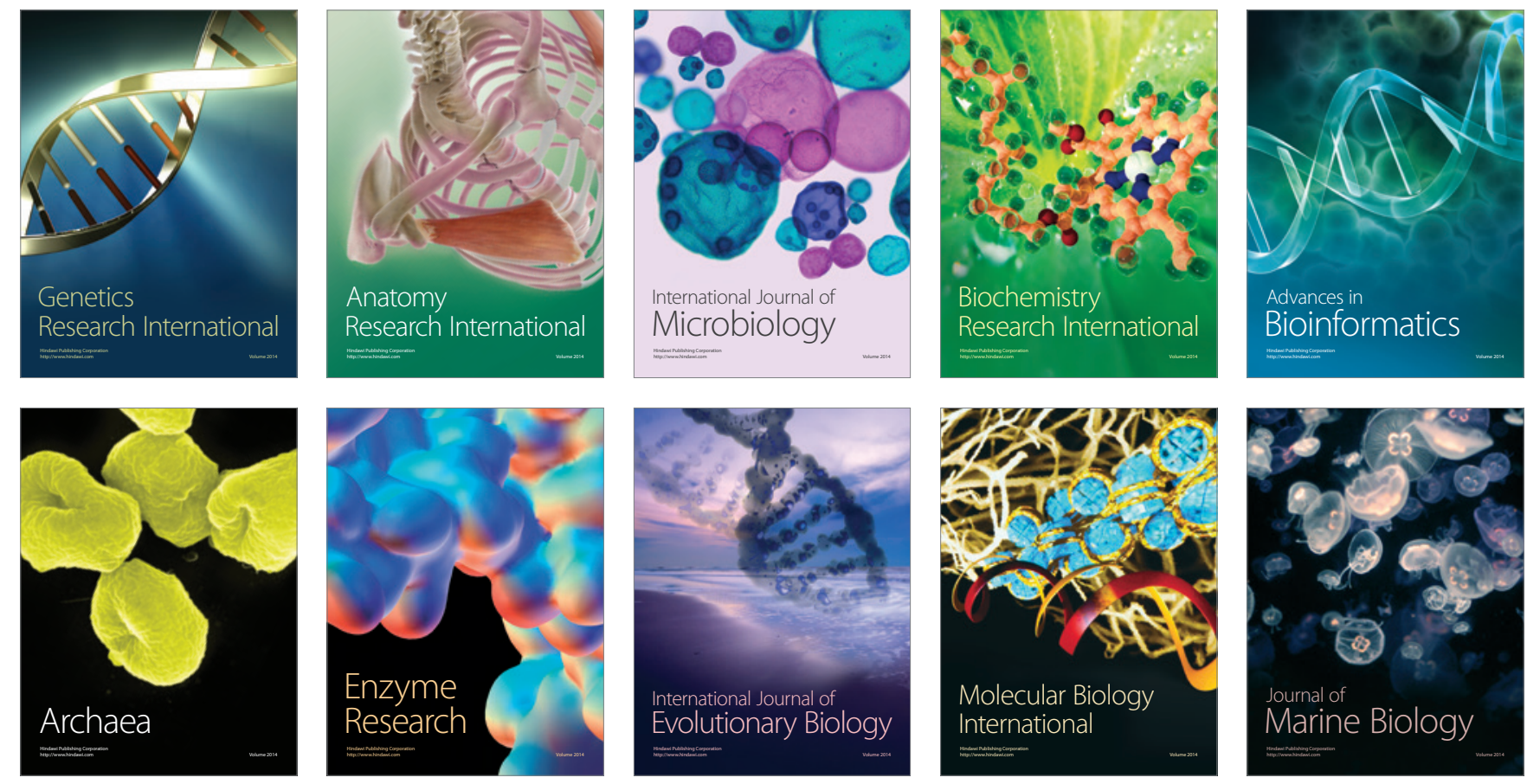